\title{
Acercamiento a la sociolingüística
}

\section{Por M.a del Carmen Marcos Casquero}

La Sociolingǘrstica, particularmente en el extranjero, es ya una disciplina establecida, aunque no claramente delimitada. Aun cuando en España hasta ahora se ha propagado poco (1), lentamente, no obstante, va tomando una posición científica, conscientes, los estudiosos del lenguaje, del papel tan importante que puede representar la Sociología en los estudios de la lengua (2).

Nuestro intento de exponer este tema persigue dos objetivos:

1.-Conocer el trabajo ya hecho. Observamos que existe una multitud de publicaciones y que su número se incrementa constantemente tanto que su revisión sólo es posible con un gran esfuerzo. Es inevitable, por ello, proceder a una selección esencial de los materiales.

2.-Con nuestro acercamiento a la Sociolingüística, tratamos de delimitar las posiciones teórico-científicas y convencer a los estudiosos de la sociología y de la lengua de la importancia y atractivo de esta combinación de especialidades.

Al abordar el estudio de una lengua se puede optar por dos caminos: el que considera la lengua como un sistema homogéneo (a la manera de los estructuralistas y transformativistas), o el que considera la lengua en su heterogeneidad y dinamismo. Este último aspecto es el que contemplan los sociolingüistas: las desviaciones de la norma, los elementos lingũísticos diferenciales (dialectales), socioculturales o estilísticos (como señaló Coseriu).

Pero lo diferencial de un habla cualquiera no suele ser representativo de toda la comunidad hablante. En efecto, junto a esos elementos diferenciales

(1) Sólo encontramos algunos nombres importantes en esta materia: Alvar, Badía, Ninyoles; e hispanohablantes como Granda o Rona.

(2) Cfr. BORREGO, Sociolingüistica rural, 1981, importante estudio sociolingüístico aplicado en Villadepera de Sayago. 
conviven otros elementos de carácter normativo; ambos tipos de elementos configuran la lengua de dicha comunidad lingü rstica.

Los fenómenos lingüísticos están determinados por ciertos factores extralingü ísticos: sexo, edad, incidencia de la norma en la comunidad, cultura, etcétera.

Pongamos un ejemplo. En el habla de El Marllo (Salamanca), cuyo estudio recogimos en nuestra memoria de Licenciatura (3), hay arcaísmos (como el pronombre átono vos o restos de las antiguas sonoras: donodilla "donocilla", dagal "zagal"...), leonesismos (imperativos con -d- conservada: sentade, $i d e . .$. ; imperativos con $-e$ final conservada, convertida en $-i$ : vai, andai...), salmantinismos y vulgarismos. Pero estos fenómenos, que difieren de la lengua estándar o normativa, no son comunes a la totalidad de hablantes: suele conservarse más en las gentes mayores, menos en los jóvenes, debido a varios factores entre los que podríamos destacar la cultura, la incidencia de los medios de comunicación, el rechazo de lo no normativo... Y en la página 5 decramos: "Los aspectos culturales son muy escasos, determinando asi un léxico derivado de su socio-econom fa, lleno de arcaísmos y vulgarismos".

Todas estas consideraciones dan idea de la importancia de los elementos extralingüísticos, socioculturales, que caen dentro del campo de la Sociolingüística, y de la necesidad de su aplicación en el estudio de una lengua.

\section{LENGUA Y SOCIEDAD}

La lengua es una actividad social que refleja las estructuras sociales de una colectividad y es al mismo tiempo parte integrante de su cultura. Por tanto, su evolución está condicionada a la del grupo que la habla. Lejos del determinismo lingüistico de Humboldt, Sapir o Whorf, habría que hablar de "relatividad" lingú ística y cultural, como apunta Lyons (4).

A veces hay coincidencias culturales entre grupos sociales distintos. Estas interacciones entre las lenguas o "intersecciones culturales" (5) son debidas a contactos entre grupos sociales y sólo excepcionalmente alcanzarían la estructura de las lenguas. Hay una relación estructura social-estructura lingüística y, como decía Meillet, los cambios de estructura social se traducen por cambios de estructura lingüística. Pero, como veremos, esto no siempre es cierto. La lengua tiene su propia inercia y sus propias condiciones de evolución, el cambio completo en una estructura social no implica un cambio en

(3) El habla de El Malllo: Contribución al Diccionario salmantino, Salamanca, 1982. Copia mecanografiada.

(4) Cfr. LYONS, Introducción, pág. 445.

15) Cfr. LYONS, Introducción, pág. 446. 
la estructura de su lengua, como se demostró en la discusión sobre la lingǘstica suscitada en la URSS en 1950. J. Stalin, con su intervención, destruyó la ideología marrista al afirmar que la lengua es común a todas las clases. Se llegó a la conclusión de que la lengua no puede considerarse en su totalidad como una superestructura determinada por la infraestructura económica y social.

Es quizá el léxico el que manifiesta de manera más evidente la relación de la lengua con todos los aspectos de la sociedad (6).

La Sociolingü ística, puesto que atiende a los aspectos pragmáticos del lenguaje, es la que tiene que estudiar las relaciones entre lengua y sociedad.

\section{NACIMIENTO DE LA SOCIOLINGÜÍSTICA Y PRECEDENTES}

Borrego (7) toma como punto de arranque de la Sociolingüística el año 1964 , fecha en que, tienen lugar dos importantes congresos dedicados a ella en Estados Unidos: el de la Universidad de California (en mayo) y el de la Universidad de Indiana (en verano), cuyas ponencias fueron publicadas por Bright y Lieberson, respectivamente, en 1966 (8). Ambos congresos recogfan anteriores estudios sobre las relaciones lengua y sociedad. Pero es a partir de esta fecha cuando se difunde esta nueva disciplina y comienza a incrementarse el número de las publicaciones.

Naturalmente, antes de 1964 existía una tradición de lingüística externa en colaboración con otras ciencias como la Sociología, la Etnografía y la Antropología. Aunque todos los trabajos estaban en la misma temática, relaciones lengua-sociedad, su posición teórico-científica no estaba delimitada, como nos lo desmuestra la distinta terminologfa que entonces aparece: "sociolingü ística", "etnolingũ ística", "lingü ística antropológica", "lingü ística social", "antropolingü ística", etcétera.

Hymes, Language in Culture, págs. 3-14, resume esta tradición en tres corrientes principales:

A) La inglesa, que considera la lengua como una actividad social y ve necesaria, para su descripción, el incluirla en un contexto extralingüístico. Las relaciones entre lengua y sociedad son de interdependencia. Incluye dentro de esta corriente los nombres de Malinowsky, Gardiner y Firth, entre otros (9).

(6) G. MATORE propone considerar la palabra no como un objeto aislado, sino como un elemento dentro de conjuntos clasificados jerárquicamente partiendo de un análisis de las estructuras sociales. Adopta un punto de vista sociológicoestructuralista y piensa que las palabras son "le reflet d'un état de société". Cf́r. La méthode en lexicologie. Domaine franfais, París, 1953.

(7) BORREGO, Sociolingüistica rural, pág. 27.

(8) W. BRIGHT, (ed.), Sociolinguistics, The Hague, Mouton, 1966. S. LIEBERSON, (ed.), Explorations in Sociolinguistics, Indiana University, 1966.

(9) Cfr., por ejemplo, A: GARDINER, Theory of Speech and Language, donde ya en 1932 sostiene que sólo puede considerarse el origen del lenguaje como resultado de condiciones sociales, tratando de dar una explicación sociológica de su origen y desarrollo. 
B) La francesa, que considera el lenguaje como un sistema heredado y socialmente compartido cuya función principal es la referencial. Las relaciones entre lengua y sociedad, vistos como dos sistemas paralelos, son de congruencia. Incluye en esta corriente nombres como los de Meillet (10), Cohen, Benveniste, Levi-Strauss, Sommerfelt (11), etcétera.

C) La estadounidense, más próxima a la francesa que a la inglesa, considera el lenguaje más como producto cultural o herecia colectiva que como un elemento de acción social. Destaca su atención al trabajo del campo en el estudio de los indios nativos, muchas veces al servicio de la etnología, la sociología y la antropología en general (12). Hymes cita, entre otros, a Boas, Sapir y Bloomfield (13).

Borrego (14) pone de manifiesto que el enfoque desde el punto de vista antropológico de Hymes deja fuera corrientes importantes como la alemana (con la cual enlazaría la estadounidense) y el pensamiento ruso de inspiración marxista. En España, las relaciones entre lenguaje y cultura fueron estudiadas por Menéndez Pidal y sus discípulos de la "Escuela de Madrid", convencidos de que "los hechos filológicos no pueden ser estudiados aisladamente, sino que necesitan ser considerados en relación con otros hechos culturales" (Catalán, Ling. Iberorrománica, pág. 27).

Por otra parte, junto a esta tradición de lingüística externa se desarrolla otra dirección lingü ística divergente: la lingüística moderna que estudia la lengua como un sistema homogéneo y estático. A este último grupo, que Labov denomina de lingüistas "asociales" (frente a los "sociales" del grupo anterior), pertenecen los estructuralistas y los cultivadores de la gramática generativa transformacional. Estos lingüistas, Saussure, Hjelmslev o Chomsky, por ejemplo, aunque reconocen en la lengua factores sociales, los relegan por considerarlos fenómenos no-lingüísticos. Así, Chomsky establece la distinción entre "competencia (el conocimiento que el hablante-oyente tiene de su lengua) y actuación (el uso real de la lengua en situaciones concretas)" (15). al decir que "lo que concierne primariamente a la teoría lin-

(10) A. MELLET en su reseña del Cours (1916) y AMADO ALONSO en su introducción a la ed. española del Cours (1945) lamenta que De Saussure, por su actitud estructural, no tomase en cuenta los seres humanos que usan el lenguaje.

(11) A. SOMMERFELT en La langue et la société, caractères soclaux dune langue de type archafque, Oslo, 1938, obra sobro los aranta de Australla, intenta poner en evidencia una correlación entre el tipo lingüistico de la sociedad aranta y su civilización social.

(12) Como consecuencia de esto, muchas veces, hay que buscar las contribuciones estadounidenses a la lingilística en publicaciones (revistas y colecciones) dedicadas a cuestiones sociológicas, etnológicas o psicológicas.

(13) El princlpal fue, quizá, Sapir, que juzgaba el lenguaje como "un guia de la realidad social". BORREGO, Sociolingilistica rural, pág. 20, considera discutible la inclusión de Bloomfield en este contexto, ya que define "la influencia de la sociedad como ajena al desenvolvimiento normal del lenguaje" y ve "la acción de elementos externos como interferencias disfuncionales".

(14) Cfr. BORREGO, Sociblinguistica rural, pág. 20.

(15) CHOMSKY, Aspectos, pág. 6. 
güistica es un hablante-oyente ideal, en una comunidad lingüística del todo homogénea, que sabe su lengua perfectamente y al que no afectan condiciones sin valor gramatical, como son limitaciones de memoria, distracciones, cambios del centro de atención e interés, y errores (característicos o fortuitos) al aplicar su conocimiento de la lengual al uso real" (16). De esta manera el objetivo de la gramática generativa transformacional será la descripción de la competencia, mientras que la actuación, a la que pertenecen los factores sociales, sería un factor obstaculizante en la aprehensión de la competencia.

Las limitaciones a que conduce la descripción del sistema lingüístico, al no introducir factores extralingüísticos, provoca reacciones entre los lingü istas e impulsa los estudios de la lingülística externa con un mayor rigor cientifico en la década de los sesenta.

Así, frente a la competencia chomskyana en el lenguaje, surge la "competencia comunicativa" de Wunderlich, Habermas o Hymes con conceptos diferentes. Para Hymes, por ejemplo, la competencia comunicativa es una medida graduable del dominio de diversos códigos verbales en una comunidad lingüística; la influencia extralingü ística puede fomentar o inhibir la posibilidad de expresión y el registro lingüístico de un individuo aunque tenga un dominio perfecto de la gramática (17).

Las objeciones a la problemática competencia/actuación no implican un rechazo de las reglas generativas, sino un intento de mostrar la interacción de la competencia lingüística y de la competencia comunicativa.

Muchos e interesantes son los trabajos realizados por los lingüistas intentando demostrar esta interacción, entre los que destacan los estudios de W. Labov sobre los usos lingüísticos en la isla de Martha's Vineyard, Massachusetts (18) o sobre la diferenciación social del habla de Nueva York (19).

Un ejemplo de Borrego (20) bastará para darnos cuenta de la necesidad de unas reglas sociolingüisticas: "Consideremos en español la frase siguiente: "El agente del orden se dirigió a uno de los manifestantes con ánimo de romperle la jeta". Una gramática GT tal como está concebida en Chomsky, Aspects, generaría esta frase sin inconvenientes. Y sin embargo tal frase queda excluida en espaniol de contextos que no tengan una intención humorística, y ello en virtud de la disonancia que supone la inserción de un modismo rabiosamente coloquial como "romper la jeta" en

(16) CHOMSKY, Aspectos, pág. 5.

(17) Cfr. HYMES, On comunicative, págs. 281 y ss.

(18) LABOV, Sobre el mecanismo.

(19) LABOV, The social stratification.

(20) BORREGO, Sociolingü istica rural, págs. 25-26. 
una secuencia de marcado tono formal (...). Si queremos que una gramática bloquee frases de este tipo (que sin duda no concuerdan con las intuiciones de un hablante nativo) es preciso introducir en ella la noción de "estilo", "registro" o "nivel de lengua" y, en consecuencia, la noción de "situación", que es ya de tipo social".

Todas estas consideraciones son la causa del arranque de la Sociolingüistica al que nos referíamos al comienzo de este apartado.

\section{CONCEPCIONES DE LA SOCIOLINGÜISTICA}

Como decíamos en la introducción, uno de nuestros objetivos es tratar de delimitar las posiciones teórico-cientificas sobre la sociolingüistica que con tanta profusión han ido surgiendo en los últimos afos. Es común a todas ellas el afirmar que existen diferenciaciones lingüísticas cuyas relaciones con la sociedad son estudiadas por la Sociolingü ística.

Pero algunos investigadores añaden una serie de precisiones que Borrego, Sociolingüística rural, págs. 28-31, resume en tres concepciones o posturas siguientes:

A) Concepción lingüistica: Centra su estudio en el análisis del sistema o diasistema. Los investigadores intentan describir la estructura interna de un sistema determinado, pero se ven obligados a considerar factores extralingü ísticos en su estudio para conseguir resultados satisfactorios. Incluye en esta tendencia sociolingüística los nombres de Labov, Alvar, Rona, López Morales, Fishman (por algunos de sus trabajos) y Darnell, entre otros.

B) Concepctón sociológica: El objeto básico de análisis es el código, es decir, el estudio de las variaciones en la lengua en una comunidad y qué determina esas variaciones. En estos trabajos se acogen gran cantidad de elementos puramente sociológicos, por los que algunos lingüistas denominan esta segunda postura "sociología del lenguaje". Borrego cita, dentro de esta tendencia, los nombres de Gadet, Fisher, Bal, Sankoff y Fishman (por algunos de sus trabajos) (21).

C) Concepción etnográfica: Centra su estudio en el concepto de comunicación. Analiza las relaciones lengua/cultura y sociedad añadiendo factores etnográficos y antropológicos: le interesa la organización completa del hablar y del comunicarse en un grupo humano específico. En este concepto de sociolingǘstica, llamado con frecuencia "etnografía del hablar", incluye los nombres de Ervin-Tripp, Grimshaw, Gumperz y Hymes.

(21) FISHMAN, Sociología del lenguaje, pág. 35, ve dos partes en la sociología del lenguaje. Una, la sociologia descripttua del lengude, pretende descubrir las normas del uso lingilístico: "¿quién habla (o escribe), qué lenguas (o variedad lingüística), a quión y cuándo y con qué fin?". La otra parte es la sociologia dinámica del lenguaje que "intenta dar contestación al interrogante: "¿qué es lo que explica las diferentes causas del cambio de la organización social del uso lingüístico y del comportamiento ante el lenguaje?". 
Por su parte, Borrego (22) cree que para que el estudio de una comunidad sea completo hay que abordar las siguientes cuestiones:

1.-Determinar qué grupos de hablantes muestran una conducta similar y cuáles son los factores sociológicos (edad, sexo, estatus profesional, cultura, etc.) que los caracterizan.

2.-Determinar las variedades lingü ísticas de una comunidad las cuales constituyen su repertorio verbal.

3.-Averiguar las reglas de uso del repertorio: cuándo y por qué se utiliza una variedad lingǘstica del repertorio y no otra. En el uso del repertorio influyen numerosos factores como las relaciones emisor-receptor, el tema, el canal de comunicación (oral, escrito, telegráfico...), el lugar (casa, clase, bar, etc.), la disposición de ánimo de los interlocutores, las intenciones del hablante y los efectos que busca lograr.

Señala Borrego "que, para determinados temas, repertorio verbal y uso no pueden separarse ni aun metodológicamente".

4.-El cambio lingüistico, tratando de "fijar sus causas, sus efectos y su desarrollo futuro". Es éste un tema fundamental de la sociolingüística (23).

5.- Las evaluaciones que los hablantes de un grupo tienen de sus propios recursos lingüísticos y de los ajenos. Es decir, la actitud del usuariơ: si valora positiva o negativamente su propia variedad lingü ística y aquéllas con las que se relaciona.

\section{METODO}

Aunque muchos son los métodos de investigación sociolingǘstica esta concepción de Borrego nos parece la más completa y pertinente. Ello no implica que el investigador agote aquí sus posibilidades. Todo lo contrario; el método a seguir tiene necesariamente que adecuarlo a los fines de la investigación.

Hudson (24) nos ofrece los estadios que suelen seguirse en todo estudio sociolingüistico: "selección de hablantes, circunstancias y variables lingü ísticas", "recogida de textos", "identificación de las variables lingüísticas y sus variantes en los textos", "procesamiento de los datos" (es decir, el número de apariciones identificadas de variantes), "interpretación de los resultados".

(22) Cfr. BORREGO, Sociolingzilistica rural, págs. 31-39.

(23) Así lo ven MARCELLESI y GARDIN, Introducción.... pág. 318: “Aquí formulamos, a partir especialmente de los trabajos de Labov y de Voloshinov... un conjunto de proposiciones -esquemas de teorización para el estudio del cambio lingü ístico, objeto esencial de una lingúística social -". Comparte esta idea también ALVAR y BORREGO.

(24) HUDSON, La sociolingüistica, pág. 157. 
Nosotros destacaremos que para obtener un buen resultado en la descripción de la lengua de un grupo determinado es importante hacer una buena selección de los informadores (educación, profesión, edad, etnia, etc.) y una acertada elaboración del cuestionario que se ha de utilizar en las encuestas. En cuanto al investigador, es evidente que su presencia cohibe con frecuencia a los hablantes creando con ello una situación formal en el momento de la encuesta contraria a la espontaneidad que se busca. Como la simple observación no daría los resultados deseados es imprescindible, como propone Labov, elegir temas de conversación que lleven a los informadores a una situación normal y coloquial.

\section{CONCLUSION}

Como hemos visto, la lengua no es totalmente homogénea. A ser una actividad social los fenómenos lingürsticos están determinados por ciertos factores extralingüísticos, socioculturales. Es tarea de la Sociolingü ística estudiar las relaciones entre lengua y sociedad.

Los enfoques en los estudios sociolingü ísticos son muy diversos, aproximándose muchas veces a otras disciplinas como la etnografía, la psicología o la antropología. Ello ha provocado que con la Sociolingüística hayan

surgido ramas como la Etnolingüística, la Psicolingüística, la Antropolingü ística, aún en proceso de definición y delimitación.

El método de investigación sociolingü ística (observación, conversación, cuestionario...) ha de ser exhaustivo y adecuarse a los fines de investigación. Los resultados obtenidos permiten ser aplicados en numerosos proyectos (25): en la enseñanza de la lengua (al proporcionar datos lingüísticos a los educadores), en la creación de gramáticas normativas, en la creación y revisión de los sistemas de escritura (la reforma ortográfica, por ejemplo, del chino o la recientemente modificada ortografía irlandesa), en alfabetización, en la formación o consolidación de nacionalidades, en medios de comunicación de masas (26), etc. En definitiva, con determinados fines pedagógicos, humanitarios, etc. Esto se denomina sociolingüistica aplicada.

(25) FISHMAN, en Sociologia del lenguaje, estudia la Sociologia aplicada del lenguaje, págs. 197 217; cita a FERGUSON con el que coincide en dividir la lingüística aplicada "en sus seis ramas americanas más comunes", algunas de las cuales citamos aquí. 214.

(26) A propósito de planificación linguïistica, cfr. GARMADI, La Sociolinguistique, págs. 185. 


\section{BIBLIOGRAFIA}

BORREGO NIETO, J.: Sociolingüistica runal. Investigación en Villadepera de Sayago, Universidad de Salamanca, 1981.

CATALAN, D.: Lingüistica Iberomománica, Madrid, Gredos, 1974.

COHEN, M.: Manual para una sociologia del lenguaje, Madrid, Ed. Fundamentos, 1973.

CHOMSKY, N.: Aspectos de la teoria de la sintaxis, Madrid, Aguilar, 1976.

CHOMSKY, N.: Reflexiones sobre el lenguaje, Barcelona, Ariel, 1979.

FISHMAN, J. A.: Sociologia del lenguaje, Madrid, Ed. Cátedra, 1979. (Es una revisión y ampliación de su obra Sociolinguistics, a brief introduction, Massachusetts, 1970.)

GARMADI, J.: La Sociolinguistique, París, Presses Universitaires de France, 1981.

HUDSON, R. A.: La Sociolinguilistica, Barcelona, Anagrama, 1981.

HYMES, D.: Language in Culture and Society. A reader in linguistics and anthropology, Nueva York, Harper International Edition, 1966. (Publicada por primera vez en 1964 en Harper and Row.)

HYMES, D.: On Communicative Competence, resumido por Pride and Holmes en Sociolinguistics, England, 1972, págs. 269-293.

LABOV, W.: The social stratification of English in New York City, Washington, Center for applied linguistics, 1966.

LABOV, W.: Sobre el mecanismo del cambio lingüistico, en Garvin y Lastra de Suárez, Antologia de Estudios de Etnolingüistica y Sociolingüistica, Universidad Autónoma de México, 1974, págs. 424-450.

LYONS, J.: Introducción a la Lingüistica teórica, Barcelona, Teide, 1975.

MARCELLESI, J. B. y GARDIN, B.: Introducción a la Sociolingüística, Madrid, Gredos, 1979.

SHLIEBEN-LANGE, B.: Iniciación a la Sociolingüistica, Madrid, Gredos, 1977.

VARIOS AUTORES: Lecruras de Sociolingüistica, Madrid, Edaf, 14, 1977. Recoge artículos de autores como Alvar, Coseriu, Catalán, Granda, etcétera. 